\title{
Diyabet Risk Farkındalığı: Bir Metropol Örneği
}

Diabetes Risk Awareness: A Metropolitan Example

Giray Erdoğan', Gülhan Coşansu²

\section{Öz}

Amaç: Bu çalışmanın amacl; diyabetli olmayan erişkin bireyleri de diyabet risk faktörlerini ve bireylerin risk farkındalıklarını belirlemektir.

Gereç ve Yöntem: Çalışma tanımlayıcı ve ilişki arayıcı tipte planlandı. Araştırmaya 18 yaş üstü, diyabetli olmayan ve çalışmaya katılmaya gönüllü olan bireyler dahil edildi. Verilerin toplanmasında Kişisel Bilgi Formu ve Tip 2 Diyabet Risk Tanılama Formu (FINDRISC) kullanıldı.

Bulgular: Araştırmaya çoğunluğu erkek $(\% 62,4)$ yaş ortalaması 48,23 $\pm 15,54$ olan 875 birey katıldı. Katılımcıların beden kütle indeksi (BKi) ortalaması $28,34 \pm 4,89 \mathrm{~kg} / \mathrm{m} 2$, olup \%39,2'si fazla tartılı, $\% 35,1$ 'i ise obezdir. Bel çevresi (BÇ) ortalaması

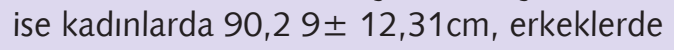
$97,38 \pm 10,34 \mathrm{~cm}$ olarak hesaplanan bireylerin sadece \% 29,8'inin bel çevresi normal değer aralığındadır. Çalışmaya katılan bireylerin diyabet risk testi (FINDRISC) puan ortalaması 10,44 $\pm 5,23$ bulundu. Kadınların puan ortalaması erkeklerden daha yüksekti ( $t=-3.37, p=0.001)$. Katılımcıların \%97'si diyabetin önemli bir hastalık olduğunu, \% 89,3'ü diyabetin önlenebilir olduğunu ifade ederken $\% 61,6$ 'sı kendini diyabet açısından riskli bulduğunu belirtti.

Sonuç: Bu araştırma, katılımcıların büyük bir kısmının bel çevresi ve BKi değerlerinin normalin üzerinde olduğunu, FINDRISC puanına göre yarıdan fazlasının orta ve üstü risk grubunda olduğunu ve yaklaşık 1/3'inin kendini diyabet açısından riskli bulmadığı yani bireysel risk farkındalığının düşük olduğunu ortaya koymuştur.

Anahtar sözcükler: Tip 2 Diyabet, Diyabet Risk Faktörleri, Farkındalık, FiNDRISC Toplum Taraması.
Kabul/ Accepted : 08.09.2021

\section{Abstract}

Aim: The aim of this study is; To determine diabetes risk factors and risk awareness of individuals without diabetes.

Material and Methods: The study was planned in a descriptive and relationship seeking type. Individuals over the age of 18 without diabetes who volunteered to participate were included in the study. Personal Information Form and Type 2 Diabetes Risk Identification Form (FINDRISC) were used to collect data.

Results: 875 individuals, most of them being male $(62,4 \%)$ with a mean age of $48,23 \pm 15,54$, participated in the study. The average body mass index (BMI) of the participants was $28.34 \pm 4.89$, $39,2 \mathrm{~kg} / \mathrm{m} 2 \%$ of them being overweight and $35,1 \%$ being obese. The waist circumference (WC) average of only $29.8 \%$ of the individuals calculated as $90,29 \pm 12,31 \mathrm{~cm}$ for women and $97.38 \pm 10,34$ $\mathrm{cm}$ for men is within the normal range. The average diabetes risk test (FINDRISC) score of the individuals participating in the study was found to be 10,44 \pm 5,23 . The mean score of women was higher than than of men $(t=-3.37, p=0.001)$. While $97 \%$ of the participants stated that diabetes is an important disease, $89.3 \%$ stated that diabetes is preventable, $61,6 \%$ stated that they found themselves in risk in terms of diabetes.

Conclusion: This study reveales that most of the participants had waist circumference and BMI values above normal, more than half of them were in the medium and above risk group according to their FINDRISC score, and approximately $1 / 3$ of them did not find themselves risky in terms of diabetes, ie they did not have individual risk awareness.

Key words: Type 2 diabetes Risk factors for diabetes, Awareness, FINDRISC, Community screening.

\footnotetext{
${ }^{1}$ Arş. Gör., Niğde Ömer Halisdemir Üniversitesi Zübeyde Hanım Sağlık Yüksekokulu, Halk Sağlığı Hemşireliği (Orcid no: 0000-0002-0685-5 I 79)

${ }^{2}$ Dr. Öğr. Üyesi, İstanbul Üniversitesi Cerrahpaşa Florence Nightingale Hemşirelik Fakültesi, Halk Sağl/ğı Hemşireliği (Orcid no: 0000-000 I -984 I -9253)
} 


\section{Giriş}

Uluslararası eğilimlere benzer olarak ülkemizde artan gelişmişlik düzeyi ile birlikte hastalık örüntüleri değişime uğramıştır. Uzun yıllar sağlık gündeminde bulaşıcı hastalıklar çok daha öncelikli iken, günümüzde bulaşııı olmayan hastalıklar ön plana çıkmıştır. Değişen yaşam koşulları, beslenme alıskanlıkları, stres ve diğer çevresel faktörler bazı hastalıkların morbidite ve mortalitesini artırmışıı (1). Diyabet bulaşıcı olmayan hastalıklar içinde önemli bir yer tutmaktadır ve yaşadığımız çağın en önemli halk sağlığı sorunlarından biridir. Görülme sıklığı tüm dünyada hızlı bir şekilde artış göstermektedir $(1,2)$. Uluslararası Diyabet Federasyonu (IDF) güncel kaynaklarda 2019 yılı için 20-79 yaş grubu arasında 463 milyon kişinin diyabetli olduğunu $(\% 9,3)$ bildirmektedir. Uluslararası otoritelerin 2030 yılı için 438 milyon olarak öngördüğü diyabetli sayısının 2019 yılında geçildiği ve Bozulmuş Glukoz toleransı olan 374 milyon prediyabetli birey olduğu da dikkate alınırsa bu salgının yıllar içinde daha da yayılacağını düşündürmektedir. Diyabete bağlı ölümlerin sayısı HIV/AIDS, Tüberküloz ve Sıtma gibi bulaşıcı hastalıklarının toplam ölüm sayısından daha fazladır. 2019 yılında dünya üzerinde 4,2 milyon insanın diyabet nedeniyle yaşamını kaybettiğini belirtirken, 2045 yılında en az 700 milyon insanın diyabetli, 548 milyon insanın da diyabet adayı olacağını öngörülmektedir (3). Uluslararası Diyabet Federasyonu Türkiye'nin, 2045 yılında dünya üzerinde en fazla diyabetli bireyin yaşayacağı 10 ülkeden biri olacağını tahmin etmektedir. Günümüzde Türkiye, \% 11,1 diyabet prevalansı ile IDF Avrupa bölgesinde en yüksek diyabet prevelansına sahip ülkedir ve 6,6 milyon erişkin diyabetli sayısı ile Almanya ve Rusya'dan sonra bölgede üçüncü sırada yer almaktadır (3). Türkiye Diyabet, Obezite ve Hipertansiyon Epidemiyolojisi Araştırmasının (TURDEP II) sonuçlarına göre, erişkin Türk toplumunda diyabet sıklığının \% 13,7 ye ulaştığı bildirilmiştir (4).

Dünya verileri ile benzer olarak ülkemizde diyabet farkındalığı da düşüktür. Diyabetlilerin yaklaşık yarııının (\% 45) hastalığın farkında olmadığı, farkındalık konusunda ciddi bir sorun olduğu bildirilmektedir (4). Türkiye Diyabeti Önleme Kontrol Programı (TDÖKP) eylem planında bu oran \% 32 olarak ifade edilmiştir (5). Diyabetli bireylerin dahi büyük bir kısmının diyabetin farkında olmadığını düşünüldüğünde, diyabet tanısı almamış ancak diyabet riski yüksek olan bireylerin de farkındalık oranlarının düşük olacağı tahmin edilmektedir. Bu süreçte diyabet risk faktörlerinin belirlenmesi diyabetin erken dönemde tanılanmasında "risk taramaları" büyük önem taşımaktadır. Toplum temelli diyabet taramalarının yararı ve maliyet etkinliği tartışmalı bir konu olmakla birlikte yapılan tarama etkinliklerinin toplumsal farkındalık yaratmak adına önemli olduğu vurgulanmaktadır (5-8). Ayrıca birçok kaynakta diyabetin önlenebilmesi ve diyabet risklerinin azaltılabilmesi için toplumsal farkındalığın artırılmasının oldukça önemli olduğu vurgulanmıştır $(5,9)$.

Tip 2 diyabetin gelişmesinde sağlıklı yaşam biçimi davranışlarını ile birlikte çevresel faktörlerin önemli rolü olduğu birçok kaynakta bildirilmektedir (9-12). Modern yaşam biçiminin benimsenmesi, insanları daha az hareket etmeye yöneltmiş ve bireylerin sağlıkı beslenme alışkanlıklarını hızla değiştirmesine sebep olmuştur. Bu durum kronik hastalık ve yaşam biçimi arasında güçlü bir ilişki olduğunu göstermektedir $(13,14)$. Özellikle değiştirilebilir risk faktörlerinin görülme sıklığı ve buna bağlı tip 2 diyabet sıklığı tüm toplumlarda, tüm yaş gruplarında giderek artmakta tip 2 diyabetin önlenebilmesi için riskli bireylerin erken tanılanması, bireylerin farkındalıklarının artıııması gerektiği düşünülmektedir. Buradan hareketle bu çalışmanın amacı; diyabetli olmayan erişkin bireylerde diyabet risk faktörlerini ve bireylerin risk farkındalıklarını belirlemektir.

\section{Gereç ve Yöntem}

\section{Araştırmanın Tipi}

Tanımlayıcı ve ilişki arayıcı tipte planlanan çalışmanın örneklem grubunu i̇stanbul'daki en büyük kent meydanlarından birinde $14 \mathrm{Kasım}$ Dünya Diyabet günü kapsamında düzenlenen ve bir hafta devam eden diyabet farkındalık etkinliğe katılan, 18 yaş üstü ve diyabetli olmayan bireyler oluşturdu. Taraması yapılan 1145 kişi arasından veri toplama araçlarında eksik bilgileri olan 270 kişi kapsam dışında bırakılarak veri analizi 875 kişi ile tamamlandı.

\section{Veri Toplama Araçları}

Verilerin toplanmasında Kişisel Bilgi Formu ve Tip 2 Diyabet Risk Tanılama Formu (Finnish Diabetes Risk Score - FINDRISC) kullanıldı. Kişisel Bilgi Formu: Araştırmacılar tarafından 
literatür doğrultusunda hazırlandı ve katılımcıların sosyo-demografik özellikleri ve antropometrik ölçüm sonuçlarını içeren 20 sorudan oluştu (1-3) Tip 2 Diyabet Risk Tanılama Formu (Finnish Diabetes Risk Score- FINDRISC): FINDRISC, 1987 yılında Prof. Jaana Lindstrom ve Prof. Jaakko Tuomilehto tarafından bireylerin tip 2 diyabet risklerini tanılamak amacıyla geliştirildi (3). Diyabet ve prediyabet açısından yüksek risk altındaki kişileri belirlemek için basit, hızlı ve invazif olmayan bir tarama aracıdır $(1,3)$. Katılımcıların 10 yı içindeki diyabet riskini ortaya koyan ve Beden Kütle İndeksi (BKi), bel çevresi, yaş, egzersiz, beslenme alışkanlıkları, kan basıncı yüksekliği öyküsü, kan glukozu yüksekliği öyküsü ve ailede diyabet öyküsünün sorgulandığı 8 soru yer almaktadır. Tip 2 Diyabet Risk Tanılama Formundan alınabilecek puanlar 0-26 arasındadır. Formdan alınan toplam puan yedi ve altında ise "Risk Derecesi Düşük", 7-11 arası "Hafif", 12-14 arası "Orta", 15-19 "Yüksek", 20 puan ve üstü "Çok Yüksek Risk" olarak tanımlanmaktadır. Türkçe dâhil olmak üzere 15 farklı dilde hazırlanmıştır. Formun kullanımı için izin gerekmemektedir.

\section{Verilerin Toplanması}

Veri toplama işlemleri İstanbul'daki en büyük kent meydanlarından birinde yapılan diyabet farkındalık etkinliğe katılan 18 yaş ve üzerinde olan bireyler ile gerçekleştirildi. Kişisel bilgi formundaki soruların katılımcılar tarafından yanıtlanmasının ardından araştırmacı tarafından bireylerin boy, tartı, bel çevresi, kan glukozu ve kan basıncı ölçümleri yapılarak beden kütle indeksi hesaplandı. Tarama esnasında random kapiller kan glukozu ölçümü yapıldı. Günün herhangi bir saatinde, açlık durumu sorgulanmadan uluslararası kalite belgesi bulunan aynı marka ve model glukometre ile kapilller tam kan örneği alındı. Taramalarda sınır değer $140 \mathrm{mg} / \mathrm{dl}$ olarak kabul edildi (15). Veri toplama işlemleri her bir katılımcı için yaklaşık $10 \mathrm{dk}$ sürdü. Veri toplama için bireylerle bir kez görüşüldü. FINDRISC puanına göre 12 puan ve üstünde alanlar ve risk puanına bakılmaksızın random kan glukozu $\geq 140 \mathrm{mg} / \mathrm{dl}$ olanlar ileri tetkikler için bir sağlık kuruluşuna yönlendirildi.

\section{İstatistiksel analiz}

Araştırma verilerinin istatistiksel analizinde SPSS 20.0 (Statistical Package for Social Sciences, İstanbul Üniversitesi) kullanıldı. Verilerinin değerlendirilmesinde Ortalama, Standart Sapma, Medyan, Frekans, Oran, Minumum, Maksimum gibi tanımlayıcı istatistiksel metodların yanısıra, normal dağılım gösteren parametrelerin iki grup karşılaştırmalarında Student t Test, normal dağılım göstermeyen iki grup karşılaştırmalarında ise Mann Whitney U Testi kullanıldı. Araştırma da ayrıca Ki-kare Testi, Oneway Anova Testi, Kruskal Wallis testi, Tukey HSD testi ve Regresyon analizinden yararlanıldı. Anlamlılık düzeyi $p<0,05$ kabul edildi.

\section{Etik IIlkeler}

Araştırma için T.C. İstanbul Üniversitesi Sosyal ve Beşerî Bilimler araştırmaları Başkanlığı Etik Kurulu'ndan etik onam (09.05.17- 55864 tarihli ve karar no:03) alındı. Katılımcılardan isteklilik ve gönüllülük ilkesi çerçevesinde araştırmaya katılım için onamları alındı.

\section{Araştırmanın Sınırlılıkları}

Çalışma da olasılıksız örnekleme yöntemi kullanılmış olmasından dolayı sonuçlar Türkiye' ye genellenemez, yalnızca araştırma grubu ile sınırlıdır. Araştırmada verilerin öz bildirim yöntemi ile toplanmış olması sosyal arzu edilirlik riskini beraberinde getirmektedir. Bu nedenle verilerin doğruluğu, taramaya katılan bireylerin bildirimleri ile sınırlıdır.

\section{Bulgular}

Araştırmaya 875 kişi katıldı. Çoğunluğu erkek olan katılımcıların $(\% 62,4)$ yaş ortalaması 48,23 \pm 15,54 dir. Katılımcıların \% 35,7'si ilkokul mezunudur ve yarıdan fazlası $(\% 59,1)$ ekonomik durumunu "orta" olarak tanımlamış, $\%$ 57'si hayatında hiç kapsamlı bir sağlık kontrolü yaptırmadığını ifade ederken \% 27,5'u sigara, $\%$ 9,9'u alkol kullandığını belirtmiştir.

Yapılan ölçümler sonucu katılımcıların BKi ortalaması 28,34 4 4,89, olup \% 39,2'si fazla tartılı, \% 35,1'i ise obezdir. Bel çevresi (BÇ) ortalaması ise kadınlarda 90,29 $\pm 12,31$ erkeklerde 97,38 $\pm 10,34$ olarak hesaplanan bireylerin sadece \% 29,8'inin bel çevresi normal değer aralığındadır (Tablo 1).

Çalışmaya katılan bireylerin diyabet risk testi (FINDRISC) puan ortalaması 10,44 \pm 5.23 bulundu. Kadınların puan ortalaması erkeklerden daha yüksekti $(t=-3.37, p=0.001)$. Grubun $\% 35,2$ 'sinin sedanter yaşam tarzına sahip olması, \%36,5'inin uygun beslenme biçimini 
Tablo 1: Katılımcıların Sosyo-Demografik, Antropometrik Özellikleri, Sağlık Öyküsü ve Alışkanlıkları

\begin{tabular}{|c|c|c|c|}
\hline \multicolumn{2}{|l|}{ Tanıtıcı özellikler (n:875) } & \multirow{2}{*}{$\begin{array}{c}\text { n } \\
22 \\
312 \\
94 \\
197 \\
250\end{array}$} & \multirow{2}{*}{$\begin{array}{l}\% \\
2,5 \\
35,7 \\
10,7 \\
22,5 \\
28,6\end{array}$} \\
\hline Eğitim Düzeyi & $\begin{array}{l}\text { Eğitimi yok } \\
\text { ilkokul (5 yıl) } \\
\text { Ortaokul (8 yıl) } \\
\text { Lise } \\
\text { Üniversite ve üzeri }\end{array}$ & & \\
\hline Ekonomik Durum & $\begin{array}{l}\text { Düşük } \\
\text { Orta } \\
\text { İyi }\end{array}$ & $\begin{array}{c}180 \\
517 \\
178\end{array}$ & $\begin{array}{l}20,6 \\
59,1 \\
20,3\end{array}$ \\
\hline $\begin{array}{l}\text { Kapsamlı sağlık kontrolü } \\
\text { (check-up) yaptırma } \\
\text { durumu }\end{array}$ & $\begin{array}{l}\text { Evet } \\
\text { Hayır }\end{array}$ & $\begin{array}{l}376 \\
499\end{array}$ & $\begin{array}{l}43,0 \\
57,0\end{array}$ \\
\hline Kronik sorun varlığı & $\begin{array}{l}\text { Evet } \\
\text { Hayır }\end{array}$ & $\begin{array}{l}370 \\
505\end{array}$ & $\begin{array}{l}42,3 \\
57,7\end{array}$ \\
\hline Kronik sorun & $\begin{array}{l}\text { Hipertansiyon } \\
\text { Solunum Sistemi Hastalıkları } \\
\text { Kalp Hastalıkları } \\
\text { Ruh Sağlığı Problemleri } \\
\text { Kas-eklem Hastalıkları } \\
\text { Tiroid } \\
\text { Sindirim Sistemi Hastalıkları } \\
\text { Diğer }\end{array}$ & $\begin{array}{l}142 \\
44 \\
55 \\
31 \\
22 \\
27 \\
27 \\
96\end{array}$ & $\begin{array}{l}16,2 \\
5 \\
6,3 \\
3,5 \\
2,5 \\
3,1 \\
3,1 \\
10,9\end{array}$ \\
\hline & & Ortalama & $\begin{array}{l}\text { Standart } \\
\text { Sapma( } \pm \text { SS) }\end{array}$ \\
\hline \multicolumn{2}{|l|}{ Yaş (Yıl) (min: 18-maks: 85) } & 48,23 & 15,54 \\
\hline \multicolumn{2}{|c|}{$\operatorname{Boy}(\mathrm{cm})(\min :$ 143-maks: 195) } & 167,79 & 9,15 \\
\hline \multicolumn{2}{|c|}{ Ağırlık (kg) (min: 45 -maks: 143) } & 79,79 & 14,77 \\
\hline \multicolumn{2}{|c|}{$\begin{array}{l}\text { Beden Kütle İndeksi (BKi) kg/m² } \\
\text { (min: } 16,65 \text {-maks: } 45,13 \text { ) }\end{array}$} & 28,34 & 4,89 \\
\hline \multicolumn{2}{|c|}{ Bel Çevresi (cm) (min: 59-maks: 140) } & 94,71 & 11,63 \\
\hline \multicolumn{2}{|c|}{ Sigara $\left(Y_{1} l\right)$ (min: 1 - maks: 50$)$} & 26,49 & 10,38 \\
\hline
\end{tabular}

Min.-Mak.: Minimum-Maksimum Puan

sürdürmemesi ve yaklaşık yarısından fazlasının $(\% 55,3)$ akrabalarında diyabet öyküsü olması dikkat çekici idi. Katılımcıların \% 49,7'si FINDRISC puanına göre orta düzey ve üstündeki risk grubuna girdiği için, \%9,9'u da kan glukozu $\geq 140 \mathrm{mg} / \mathrm{dL}$ olduğu için tanı amaçlı bir sağlık kuruluşuna yönlendirildi.

Bu çalışmada katılımcıların yaklaşık yarısı düşük risk - hafif risk grubunda olmasına rağmen, herhangi bir müdahale yapılmazsa 117 kişinin gelecek 10 yıl içinde diyabet tanısı alma olasılığı bulunduğu hesaplandı (Tablo 2).

Araştırmada, risk skoru < 15 olan kişiler "Düşük Riskli" bireyler olarak gruplandırılırken, puanı $\geq 15$ olanlar "Yüksek Riskli" bireyler olarak gruplandırıldı. Risk gruplarına göre bazı sosyodemografik özellikler ve sağlık alışkanlıkları karşılaştırıldı (Tablo 3). 
Tablo 2: Diyabet Risk Faktörleri Dağııımı

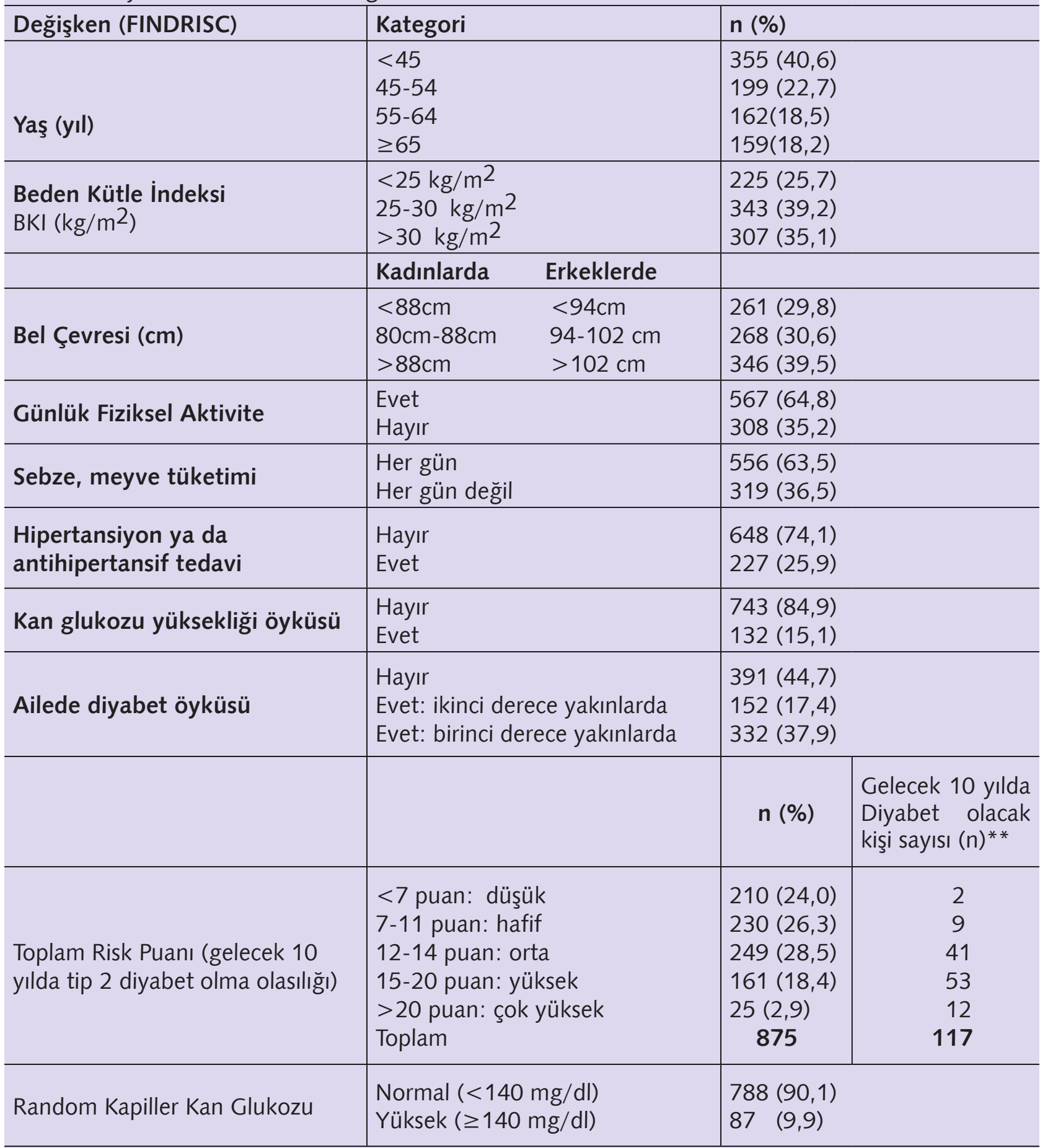

Ortalama $( \pm$ SS)

Risk puanı (FINDRISC)

(min:0 max 0-maks: 26)

$10,44 \pm 5,23$

Random Kapiller Kan Glukozu(mg/dl)

(min: 64-maks: 541)

$11,26 \pm 34,49$

"Fiziksel aktivite ve kalori harcanan aktiviteler dahil olmak üzere günde en az 30 dk fiziksel egzersiz.

** Gelecek 10 yılda diyabet teşhisi konulabilecek kişi sayısı 
Tablo 3: Sosyodemografik Özellikler ve Sağlık Alışkanlıklarının Diyabet Risk Gruplarına Göre Karşılaştırılması

\begin{tabular}{|c|c|c|c|}
\hline Değişkenler & $\begin{array}{l}\text { Düşük Risk } \\
\text { (<15 puan) } \\
\text { (n: } 689) \\
n(\% 78,7)\end{array}$ & $\begin{array}{l}\text { Yüksek Risk } \\
\text { ( } \geq 15 \text { Puan) } \\
\text { (n: 186) } \\
n(\% 21,3)\end{array}$ & $\begin{array}{l}\text { İstatistik } \\
\text { Test-p value }\end{array}$ \\
\hline \multicolumn{4}{|l|}{ Cinsiyet } \\
\hline Kadın & $242(\% 73,6)$ & $87(\% 26,4)$ & \multirow{2}{*}{$\begin{array}{l}x^{2}=2,909 \\
p=0.004\end{array}$} \\
\hline Erkek & $447(\% 81,9)$ & $99(\% 18,1)$ & \\
\hline \multicolumn{4}{|l|}{ Ekonomik durum } \\
\hline Düşük & $133(\% 73,9)$ & $47(\% 26,1)$ & \multirow{3}{*}{$\begin{array}{l}x^{2}=3,206 \\
p=0.201\end{array}$} \\
\hline Orta & $413(\% 79,9)$ & $104(\% 20,1)$ & \\
\hline Yüksek & $143(\% 80,3)$ & $35(\% 19,7)$ & \\
\hline \multicolumn{4}{|l|}{ Medeni Durum } \\
\hline Evli & $471(\% 76)$ & 149(\% 24) & \multirow{2}{*}{$\begin{array}{l}x^{2}=-3,127 \\
p=0.002\end{array}$} \\
\hline Bekar & $218(\% 85,5)$ & $37(\% 14,5)$ & \\
\hline \multicolumn{4}{|l|}{ Eğitim Durumu } \\
\hline Eğitimi yok & $16(\% 72,7)$ & $6(\% 27,3)$ & \multirow{6}{*}{$\begin{array}{l}x^{2}=19,761 \\
p=0,001\end{array}$} \\
\hline ilkokul & $223(\% 71,5)$ & $89(\% 28,5)$ & \\
\hline Ortaokul & $80(\% 85,1)$ & $14(\% 14,9)$ & \\
\hline Lise & $156(\% 79,2)$ & $41(\% 20,8)$ & \\
\hline Yüksekokul/Üniversite & $185(\% 85,3)$ & $32(\% 14,7)$ & \\
\hline Lisansüstü Eğitim & $29(\% 87,9)$ & $4(\% 12,1)$ & \\
\hline \multicolumn{4}{|l|}{ Sigara Kullanımı } \\
\hline Hiç içmedi & $335(\% 79)$ & $89(\% 21)$ & \multirow{3}{*}{$\begin{array}{l}x^{2}=7,490 \\
p=0,024\end{array}$} \\
\hline Bıraktı & $153(\% 72,9)$ & $57(\% 27,1)$ & \\
\hline Halen içiyor & $201(\% 83,4)$ & $49(\% 16,6)$ & \\
\hline \multicolumn{4}{|l|}{ Alkol Kullanımı } \\
\hline Evet & $64(\% 73,6)$ & $23(\% 26,4)$ & \multirow{2}{*}{$\begin{array}{l}x^{2}=-1,244 \\
p=0,214\end{array}$} \\
\hline Hayır & $625(\% 79,3)$ & $163(\% 20,7)$ & \\
\hline \multicolumn{4}{|l|}{ Fiziksel Egzersiz } \\
\hline Evet & $488(\% 86,1)$ & $79(\% 13,9)$ & \multirow{2}{*}{$\begin{array}{l}x^{2}=51,623 \\
p<0.001\end{array}$} \\
\hline Hayır & $201(\% 65,3)$ & $107(\% 34,7)$ & \\
\hline \multicolumn{4}{|l|}{ Sebze Meyve Tüketimi } \\
\hline Evet & $447(80,4)$ & $109(\% 19,6)$ & \multirow{2}{*}{$\begin{array}{l}x^{2}=2,489 \\
p=0.115\end{array}$} \\
\hline Hayır & $242(\% 75,9)$ & $77(\% 24,1)$ & \\
\hline \multicolumn{4}{|l|}{ Ailede Diyabet Öyküsü } \\
\hline Hayır & $363(\% 92,8)$ & $28(\% 7,2)$ & \multirow{2}{*}{$\begin{array}{l}x^{2}=83,910 \\
p<0.001\end{array}$} \\
\hline Evet & $326(\% 67,4)$ & $158(\% 32,6)$ & \\
\hline \multicolumn{4}{|c|}{ Kan Glukozu Yüksekliği Öyküsü } \\
\hline Hayır & $649(\% 87,3)$ & $94(\% 12,7)$ & \multirow{2}{*}{$\begin{array}{l}x^{2}=217,913 \\
p<0.001\end{array}$} \\
\hline Evet & $40(\% 30,3)$ & $92(\% 69,7)$ & \\
\hline
\end{tabular}




\begin{tabular}{|c|c|c|c|}
\hline \multicolumn{4}{|c|}{ Hipertansiyon ya da Antihipertansif Tedavi } \\
\hline Hayır & $566(\% 87,3)$ & $82(\% 12,7)$ & \multirow{2}{*}{$\begin{array}{l}x^{2}=110,439 \\
p<0.001\end{array}$} \\
\hline Evet & $123(\% 54,2)$ & $104(\% 45,8)$ & \\
\hline $\begin{array}{l}\text { Kronik Hastalık } \\
\text { Hayır } \\
\text { Evet }\end{array}$ & $\begin{array}{l}437(\% 86,5) \\
252(\% 68,1)\end{array}$ & $\begin{array}{l}68(\% 13,5) \\
118(\% 31,9)\end{array}$ & $\begin{array}{l}x^{2}=43,317 \\
p<0.001\end{array}$ \\
\hline \multicolumn{4}{|l|}{ Random Kan Glukozu } \\
\hline$<140 \mathrm{mg} / \mathrm{dl}$ & $647(\% 82,1)$ & $141(\% 17,9)$ & \multirow{2}{*}{$\begin{array}{l}x^{2}=51,571 \\
p<0.001\end{array}$} \\
\hline \multirow[t]{2}{*}{$\geq 140 \mathrm{mg} / \mathrm{dl}$} & $42(\% 48,3)$ & $45(\% 51,7)$ & \\
\hline & Ortalama (SD) & Ortalama (SD) & \\
\hline Yaş (yıl) & $46.32(0,60)$ & $55,32(0,85)$ & $t=-7,015 p<0.001$ \\
\hline BKI $(\mathrm{kg} / \mathrm{m} 2)$ & $27,31(0,17)$ & $32,19(0,31)$ & $\begin{array}{l}t=12,572 \\
p<0.001\end{array}$ \\
\hline Bel Çevresi (cm) & $92,63(0,43)$ & $102,43(0,68)$ & $\begin{array}{l}t=10,524 \\
p<0.001\end{array}$ \\
\hline Sistolik Kan Basıncı (mmHg) & $119,28(0,62)$ & $126,70(1,36)$ & $\begin{array}{l}t=-4,826 \\
p<0.001\end{array}$ \\
\hline Diyastolik Kan Basıncı (mmHg) & $71,13(0,44)$ & $75,02(0,94)$ & $\begin{array}{l}t=-3.544 \\
p<0.001\end{array}$ \\
\hline $\begin{array}{l}\text { Random Kan Glukozu } \\
(\mathrm{mg} / \mathrm{dl})\end{array}$ & $107,30(1,05)$ & $125,48(3,70)$ & $t=-4.525 p<0.001$ \\
\hline
\end{tabular}

Bireylerin büyük çoğunluğunun (\% 78,7) düşük riskli grupta yer aldığı, grubun $\% 21,7^{\prime}$ sinin yüksek riskli grupta olduğu tespit edildi. Kadınların $\left(x^{2}=2,909, p=0.004\right)$, evli olanların $\left(x^{2}=-3,127, p=0.002\right)$ düşük eğitim seviyesine sahip olanların $\left(x^{2}=19,761, p=0,001\right)$, egzersiz yapmayanların $\left(x^{2}=51,623, p<0.001\right)$, ailesinde DM öyküsü olanların $\left(x^{2}=83,910, p<0.001\right)$, geçmişinde kan glukozu yüksek ölçülmüş olanların $\left(x^{2}=217,913, p<0.001\right)$ kan basıncı yüksekliği-antihipertansif ilaç kullanımı öyküsü olanların $\left(x^{2}=110,439, p<0.001\right)$, kronik hastalığa sahip olanların $\left(x^{2}=43,317, p<0.001\right)$ ve kan glukoz düzeyi sınır değerin üstünde olanların $\left(x^{2}=51,571, p<0.001\right)$ birçoğunun yüksek risk grubunda olduğu bulundu. Ekonomik durum, alkol kullanım durumu ve beslenme biçimine göre gruplar arasında fark bulunmadı $(p>0.05)$. Yüksek risk grubundakilerin yaş $(t=-$ $7,015 p<0.001)$, BKI $(t=12,572, p<0.001)$ bel çevresi $(t=10,524, p<0.001)$, sistolik kan basıncı $(t=-4,826, p<0.001)$, diyastolik kan basıncı $(t=-3.544, p<0.001)$ ve kan glukozu $(t=-4.525$ $p<0.001)$ değerleri yüksek bulundu. Bu sonuçlar istatistiksel olarak anlamlı idi (Tablo 3).
Katılımcıların diyabet risk puanını yordadığı düşünülen bağımsız değişkenler çoklu "Doğrusal Regresyon Analizi" ile değerlendirildi (Tablo 4). Bulgulara göre katılımcıların Cinsiyet, Yaş, Bel Çevresi, BKi, Fiziksel Aktivite, Aile Öyküsü, Hipertansiyon, Kronik Hastalık ve Random Kapiler Glukozu, değişkenleri tarafından \% 80,3 oranında açıklandı. Kurulan bu model istatistiksel olarak anlamlı bulundu ( $F=392,591, p<0,001)$. Cinsiyet, yaş, bel çevresi, BKi, fiziksel aktivite, aile öyküsü, hipertansiyon, kronik hastalık ve random kapiler glukozu değişkenlerinin modele katkısı istatistiksel olarak anlamlı bulunurken $(p<0,05)$ kronik hastalık değişkeninin modele katkısı istatistiksel olarak anlamlı bulunmadı $(p>0,05)$. Modele en fazla hipertansiyon, yaş ve BKi değişkenlerinin etki ettiği saptandı.

Katılımcıların \%97'si diyabetin önemli bir hastalık olduğunu, \% 89,3'ü diyabetin önlenebilir olduğunu ifade ederken \%61,6'sı kendini diyabet açısından riskli bulduğunu belirtti. Kendini riskli bulanların FINDRISC puan ortalaması kendini riskli bulmayanlara göre yüksek hesaplandı ve bu sonuç istatistiksel olarak anlamlı idi 
Tablo 4: Bağımsız Değişkenlerin Diyabet Riskine Etkisi

\begin{tabular}{|c|c|c|c|c|}
\hline & B & $\operatorname{Beta}(\beta)$ & $\mathrm{t}$ & $\mathbf{P}$ \\
\hline (Sabit) & -24.824 & & -27.547 & .000 \\
\hline Cinsiyet & 1,160 & 107 & 5,825 & 000 \\
\hline Yaș & 100 & 298 & 16,113 & 000 \\
\hline Bel Çevresi & 107 & 238 & 8,113 & 000 \\
\hline BKI & 1,322 & 221 & 13,094 &, 000 \\
\hline Fiziksel Aktivite & 269 & 252 & 9,270 & 000 \\
\hline Ailede Diyabet Öyküsü & 1,089 & 199 & 12,809 &, 000 \\
\hline Hipertansiyon & 5,025 & 477 & 30,570 & 000 \\
\hline Kronik Hastalık & 209 & 020 & 1,111 & 267 \\
\hline Random Kan Glukozu & 013 & 089 & 5,817 & 000 \\
\hline
\end{tabular}

$(t=-5.21, p<0.001)$. Bu sonuç aynı zamanda grubun \% 38,4 ünün diyabet konusunda bireysel farkındalı̆ıııı olmadığııı gösterdi.

\section{Tartışma}

Tip 2 diyabet akut ve kronik komplikasyonlara yol açan ve erken ölüm riskini artıran; insidans ve prevelansı tüm toplumlarda giderek artan kronik bir hastalıktır (1-3). Araştırmada toplum taramasına katılan bireylerin diyabet gelişme riski ve diyabet riskine etki eden ilişkili faktörler incelendi. IDF, risk anketleri-formları kullanılarak toplum taramaları yapılmasını ve yüksek riskli bireylerin belirlenmesini, ardından ikinci aşamada bu yüksek riskli bireylerde kan glukozu ölçümü yapılmasını önermektedir $(3,8,10)$. Bu araştırmada taramaya katılan bireylerin diyabet risk düzeyleri FINDRISC anketi ile değerlendirildi. Yaş ortalaması $48,23 \pm 15,54$ olan bireylerin FINDRISC puan ortalamasının $10,44 \pm 5,23$ olduğu hesaplandı. FINDRISC kullanarak yapılan çalışmalar incelendiğinde risk puan düzeylerinin birbirinden çok farklı olduğu ve bu farkın çalışma gruplarının yaş ortalaması ve ilişkili olduğu görüldü. Benzer yaş grubunda Bayındır Çevik ve ark. (2016) nın yaptı̆̆ı çalışmada risk puan ortalaması (FINDRISC) $11.99 \pm 6,21$, Makrilakis ve ark. (2011) 12,6 \pm 4,9 ve Meijnikman ve ark. (2017) nın 11,0 44,0 olarak bulduğu bildirildi (16-18).

Katılımcılar FINDRISC puanına göre düşük riskli $(<15)$ ve yüksek riskli $(>15)$ olarak kategorize edildiğinde bireylerin \% 78,7 sinin yüksek, \% 21,3' ünün düşük risk grubunda olduğu saptandı. Literatürde çalışmamızla benzer sonuçları içeren araştırmalar olduğu gibi $(11,17,19)$ farklı sonuçları içeren çalışmalarda bulunmaktadır (20-21).

$\mathrm{Bu}$ araştırmada taramaya katılan bireylerin $\% 37,9^{\prime}$ unun birinci derece akrabalarında,
\%17,4' ünün ise ikinci derece akrabalarında diyabet öyküsü olduğu belirlendi. Ülkemizde yapılmış olan başka çalışmalarda benzer oranlar rapor edilmiştir $(11,16)$. Toplumlarda diyabet görülme oranı ile ailede diyabet öyküsü sıklığının çok yakından ilişkili olduğu bilinmektedir.

Ülkemizdeki diyabet prevalansının giderek arttığı düşünüldügünde bu oranların çok yüksek olması şaşırtııı bulunmadı. Kuveyt ve Küba' da yapılan çalışmalarda benzer sonuçların elde edildiği raporlandı (21-22).

Taramaya katılan bireylerin yarıya yakını $(\% 39,2)$ aşırı kilolu, üçte birinden fazlası $(\% 35,1)$ obez bulundu. Buradan hareketle çalışmaya katılan 875 katılımcının \% 74,3 ü'nün kilo problemi olduğu görülmektedir. Ayrıca bireylerin bel çevresi ortalaması 104,3 $\pm 10,90 \mathrm{~cm}$ olarak bulundu. Bu oranlar Türk toplumunda yapılmış başka çalışmalar ile karşılaştırıldığında bir hayli yüksektir $(16,23)$. Bu yüksekliğin temel sebeplerinden birinin zaman içerisinde toplumun sağılıksız beslenme alıskanlığını kazanması olduğu düşünülmektedir. Bir diğer sebep ise katılımcıların egzersiz yapma durumudur.

Egzersiz yapmanın diyabet riskine etkisi birçok araştırmada bildirilmiştir (24-25). Bu çalışmada egzersiz yapmayan bireylerin oranının \% 35,2 olarak hesaplandı. Çalışma bu yönüyle yapılan diğer araştırmalardan farklıık göstermektedir ve bulunan bu sonuç birçok araştırma sonucundan daha düşüktür $(16,19,26)$. Grubun neredeyse 3'te 2 sinin günde $30 \mathrm{dk}$ ve üzeri egzersiz yapmasına karşın diyabet risk puan ortalamasının yüksek olması düşündürücüdür.

Beslenme alışkanlıkları diyabet riskine doğrudan etki etmektedir. Çalışma grubunun $\% 63,5 \mathrm{i}$ her gün meyve-sebze tükettiğini ifade etmiştir. 
Bu bulgu diğer bazı çalışmalardan daha düşük olmakla birlikte $(16,27)$, bazı çalışmalardan $(21,22)$ da yüksektir.

Bu çalışmada katılımcıların hipertansiyon (kan basıncı yüksekliği ya da antihipertansif tedavi alma) oranı Türk Hipertansiyon Prevalans Çalışması raporundaki \% 31,8 lik orana ve Bayındır Çevik ve ark (2016) nın yaptığı çalışma sonucuna $(\% 24,6)$ benzer olarak $\% 25,9$ bulundu $(16,28)$.

Bireyin geçmişteki kan glukozu yüksekliği öyküsü, Tip 2 diyabet için tanımlanan risk faktörlerinin arasındadır (1). Araştırma grubunun \% 15,1 geçmişinde kan glukozunun yüksek olarak ölçüldügünü bildirmiştir. Bu oran Naranjo ve ark. (2013) \% 16,8 olan bulgusu ile benzerlik gösterirken, Awad ve ark. (2015) bulgusundan daha yüksektir $(21,22)$.

Birçok kaynakta toplum temelli diyabet taramalarının yararı ve maliyet etkinliği tartışmalı bir konu olmakla birlikte yapılan tarama etkinliklerinin özellikle toplumsal farkındalık yaratmak adına önemli olduğu vurgulanmaktadır (5-8). Tüm dünyada olduğu gibi ülkemizde de diyabet farkındalığı düşüktür. Bu çalışmada taramaya katılan bireylerin \% 38,4 ünün diyabete yönelik bireysel farkındalığa sahip olmadığı belirlendi. Türkiye' de yaklaşık 26 bin kişi ile yapılan bir çalışmada, bireylerin yaklaşık yarısının $(\% 45,5)$, Türkiye Diyabeti Önleme ve Kontrol Programında grubun \%32' sinin diyabetin farkında olmadığı bildirildi (4). Başka bir araştırmada katılımcıların diyabet farkındalık düzeyleri çalışma verilerimizle uyumlu olarak \% 33,7 olarak bulundu (29). Alenazi ve ark. (2020) üniversite öğrencileri ile yaptığı araştırmada diyabet farkındalık düzeylerini alt boyutlara (Diyabetin tanılanması, diyabet sebebi, diyabet belirtileri, diyabet komplikasyonları) indirgemiş ve özellikle katılımcıların \% 80,6 sının diyabeti tanımlanmasında yetersiz olduğunu yani farkındalıklarının olmadığını bildirmiştir (31).

\section{Sonuç}

Sonuç olarak bu çalışma, incelenen grubun kilo probleminin olduğunu, 1/3 inden fazlasının fiziksel aktivite düzeyinin yetersiz olduğunu ve sağlıklı beslenmediğini, yarıdan fazlasının aile öyküsünde diyabetli birey olduğunu FINDRISC puanına göre yarıdan fazlasının orta ve üstü risk grubunda olduğunu, bununla birlikte yaklaşık 1/3'ünün kendini diyabet açısından riskli bulmadığını yani risk farkındalığının olmadığını ortaya koymuştur. Grubun risk puanı ortalaması yüksek olmamakla birlikte özellikle değiştirilebilir risklerin yoğun olması bu gruba yönelik sağlığı koruma ve geliştirme programlarının planlanmasının bir zorunluluk olduğunu düşündürmektedir.

\section{Teşekkür}

Araştırmanın verilerinin toplanmasına verdikleri büyük destek ve özverili çalışmalarından dolayı Feza KOÇ, Sümeyye KALAYCI, Betül DAĞ ve Büşra KANIBOZ a teşekkür ederim.

İletişim: Arş. Gör. Giray Erdoğan

E-Posta: giray.erdogan@hotmail.com

\section{Kaynaklar}

1. Türkiye endokrinoloji ve metabolizma derneği (TEMD) diabetes mellitus ve komplikasyonlarının tanı, tedavi ve izlem kılavuzu-2020. Erişim Tarihi: 21.01.2021 http://temd.org.tr/admin/ uploads/tbl_kilavuz/20200625154506-2020tbl_ kilavuz86bf012d90.pdf

2. World Health Organization (WHO 2016). tes Erişim: 19.01.2021, http://www.who.int/ diabetes/global-report/en/

3. International Diabetes Federation (IDF 2019). Diabetes Atlas) 9th ed. Erişim Tarihi:26.01.2021. https://idf.org/e-library/ epidemiology-research/diabetes-atlas/159-idfdiabetes-atlas-ninth-edition-2019.html

4. Satman, I., Omer, B., Tutuncu, Y., Kalaca, S., Gedik, S., \& Dinccag N, et al.(2013). Twelveyear trends in the prevalence and risk factors of diabetes and prediabetes in Turkish adults. Eur J Epidemiol. 28 (2): 169-180.

5. T.C. Sağlık Bakanlığı. Türkiye Diyabet Önleme ve Kontrol Programı Eylem Planı (2011-2014). Ankara: Anıl Matbaası, 2011

6. West, S. D., Groves, D. C., Lipinski, H. J., Nicoll, D. J., Mason, R. H., Scanlon, P. H., \& Stradling, J. R. (2010). The prevalence of retinopathy in men with Type 2 diabetes and obstructive sleep apnoea. Diabetic Medicine, 27(4), 423-430.

7. Grech, M., \& Chaney, D. (2014). Screening for type 2 diabetes and pre-diabetes in general practice: a descriptive study of Maltese practices. Primary care diabetes, 8(3), 224-230.

8. International Diabetes Federation, 2012 Clinical Guidelines Task Force Global Guideline for Type 2 Diabetes (IDF Global Guideline 2012). Erişim Tarihi: 22.11.2020 http://www.idf.org/sites/ default/files/IDF-Guideline-for-Type-2-Diabetes. pdf

9. Coşansu, G. (2015). Diyabet: Küresel bir salgın 
hastalık. Okmeydanı Tıp Dergisi, 31(ek sayı), 1-6.

10. American Diabetes Association (ADA) (2020).

Prevention or Delay of Type 2

Diabetes. Diabetes Care, 2020;43(Suppl. 1): S32S36

11. Erdoğan, G., \& Coşansu, G. Taksi Şoförlerinin Sağlıklı Yaşam Biçimi Davranışlarının

Belirlenmesi. Sürekli Tıp Eğitimi Dergisi, 26 (5) 144-150.

12. Spruijt-Metz D, O'Reilly GA, Cook L, Page KA, Quinn C. Behavioral contributions to the pathogenesis of type 2 diabetes. Curr Diab Rep 2014, 14(4): 475.

13. Rozmus $C L$, Evans R, Wysochansky M, Mixon D. An Analysis of Health Promotion and Risk Behaviors of Freshman College Students in a Rural Southern Setting. Journal of Pediatric Nursing. February 2005; 20 (1): 25-33.

14. Dickey, R. A., \& Janick, J. J. (2001). Lifestyle modifications in the prevention and treatment of hypertension. Endocrine practice, 7(5): 392-399.

15. American Diabetes Association (ADA) (2000). Screening for Type 2 Diabetes. Diabetes Care, 2000; 23(Suppl. 1):S20-S23.

16. Bayındır Çevik, A., Karaaslan, M. M., Koçan, S., Pekmezci, H., Şahin, S. B., Kırbaş, A., \& Ayaz, T. (2016). Prevalence and screening for risk factors of type 2 diabetes in Rize, Nourtheast Turkey: findings from a population-based study. Primary care diabetes, 10(1): 10-18.

17. Makrilakis, K., Liatis, S., Grammatikou, S., Perrea, D., Stathi, C., Tsiligros, P., \& Katsilambros, N. (2011). Validation of the Finnish diabetes risk score (FINDRISC) questionnaire for screening for undiagnosed type 2 diabetes, dysglycaemia and the metabolic syndrome in Greece. Diabetes \& metabolism, 37(2): 144-151.

18. Meijnikman, A. S., De Block, C. E., Verrijken, A., Mertens, I., \& Van Gaal, L. F. (2018).

Predicting type 2 diabetes mellitus: a comparison between the FINDRISC score and the metabolic syndrome. Diabetology \& metabolic syndrome, 10(1), 1-6.

19. Atayoglu, A. T., Inanc, N., Başmisirli, E., \& Çapar, A. G. (2020). Evaluation of the finnish diabetes risk score (FINDRISC) for diabetes screening in Kayseri, Turkey. Primary care diabetes, 14(5), 488493.

20. Nnamudi, A. C., Orhue, N. E. J., \& ljeh, I. I. (2020). Assessment of the FINDRISC tool in predicting the risk of developing type 2 diabetes mellitus in a young adult Nigerian population. Bulletin of the National Research Centre, 44(1), 1-9. Böhme, P., Luc, A., Gillet, P., \& Thilly, N. (2020).

21. Awad, A. I., \& Alsaleh, F. M. (2015). 10-Year Risk Estimation for Type 2 Diabetes Mellitus and Coronary Heart Disease in Kuwait: A CrossSectional Population- Based Study. PloS one, 10(1), e0116742.

22. Naranjo, A. A., Rodríguez, Á. Y., Llera, R. E., $\&$ Aroche, R. (2013). Diabetes risk in a Cuban primary care setting in persons with no known glucose abnormalities. MEDICC review, 15(2): 16-19.

23. T.C. Sağlık Bakanlığı Sağlık Araştırmaları Genel Müdürlüğü. (2014). Türkiye Beslenme ve Sağlık Araştırması (TSBA) 2010: Beslenme Durumu ve Alışkanlıklarının Değerlendirilmesi Sonuç Raporu. Yayın No: 931, Ankara

24. Kulak E, Berber B, Temel H, Kutluay SN, Yıldırım $M$, Dedeoğlu FN, Cifcili $S$, Save D. Aile hekimliğine başvuran bireylerde tip 2 diyabet risk duzeyinin belirlenmesi. Turk Aile Hek Derg. 2019;23(1):2030.

25. BÜLBÜL, E., ÇELIK, S., ALÇiçEK, H., DINDAR, A., FURTANA, M., GÜNAL, M., ... \& YILMAZ, A. Hemşirelik Öğrencilerinde Diyabet Riski ve Sağlıklı Yaşam Biçimi Davranışlarının Belirlenmesi. Türkiye Diyabet ve Obezite Dergisi, 4(3), 230-238.

26. Cosansu G, Celik S, Ozcan S, Olgun N, Yıldırım N, Gulyuz Demir $\mathrm{H}$. Determining type 2 diabetes risk factors for the adults: A community based study from Turkey. Prim Diabetes Care. 2018;12(5):409415.

27. Hellgren, M. I., Petzold, M., Björkelund, C., Wedel, H., Jansson, P. A., \& Lindblad, U. (2012).

Feasibility of the FINDRISC questionnaire to identify individuals with impaired glucose tolerance in Swedish primary care. A crosssectional population-based study. Diabetic Medicine, 29(12): 1501-1505.

28. Arıcı, M., Altun, B., Erdem, Y., Derici, Ü., Nergizoğlu, G., Turgan, Ç., ... \& Çağlar, Ş. (2012). Türk Hipertansiyon Prevalans Çalışması. Türk Hipertansiyon ve Böbrek Hastalıkları Derneği. Internet erişimi: http://www. turkhipertansiyon.org/pdf/Turk_Hipertansiyon Prevalans Calismasi Ozeti-1. pdf.

29. Selçuk, K. T., \& Ünal, B. (2013). Bigadiç'te 45-74 yaş bireylerde diyabet prevalansı ve farkındalık durumunun belirleyicileri/Determinants of prevelance and awareness of diabetes in a population aged 45-74 in Bigadic. Türkiye Halk Sağlığı Dergisi, 11(3), 160-173.

30. Adedokun, A. O., Ter Goon, D., Owolabi, E. O., Adeniyi, O. V., \& Ajayi, A. I. (2019). Prevalence, awareness, and determinants of type 2 diabetes mellitus among commercial taxi drivers in buffalo city metropolitan municipality South Africa: a cross-sectional survey. Medicine, 98(9).

31. Alenazi, M. A., Alenezi, S. H., Alhablani, M. N., Alanazi, M. A. M., Alenazi, W. H., AlQahtani, M. S., .. \& Mahzari, Q. A. (2020). Knowledge and awareness of diabetes mellitus disease among high school students in King Abdulaziz Military City, Tabuk, Saudi Arabia. Open Access Macedonian Journal of Medical Sciences, 8(E), 91-97. 